\title{
Solar PV Performance-Issues and Challenges
}

\author{
Subhash Kumar ${ }^{1}$, Dr. Tarlochan kaur ${ }^{2}$ \\ ME Scholar, EED, PEC University of Technology, Chandigarh, India ${ }^{1}$ \\ Associate Prof., EED, PEC University of Technology, Chandigarh, India ${ }^{2}$
}

\begin{abstract}
The output of the solar photovoltaic (PV) arrays is not constant throughout the day. It varies with time. Output change with the climatic condition, it varies in summer winter and rainy season. So we cannot get the maximum output all the time. This paper discuss the factor that effect solar PV performance in different environment condition and location of PV module. These factors may be orientation of the PV module, tracking the sun, temperature of PV module, incidence/tilt angle of the PV panel, shading of the panel, mounting rooftop material, mounting height, solar irradiance, type of PV module, and dust on module. Above said are some important factor that significantly affects the performance of solar photovoltaic cells. So need to be discussed.
\end{abstract}

Keywords: Solar PV panel characteristics, Performance, factor affecting.

\section{INTRODUCTION}

Solar energy is most readily available source of energy. It is Non-polluting and maintenance free. To make best use of the solar PV systems the output is maximized by suitable methods. For this PV solar cell is used that uses PN junction to directly convert the sunlight into electricity. The voltage and current both are the function of light falling on this. But too much isolation of the cell cause the saturation eventually the power output reduced because of increase in mobility of electron and increase in temperature. The other problem is tracking of the sun according to the PV module i.e. orienting the panel in such a direction so that panel receives maximum irradiance. MPPT is important parameter to be considered for power output of panel. Irradiance falling on the surface is not constant all the time due to fluctuation of environmental condition temperature change and irradiance level changes. Due to this IV curve changes and hence MPP algorithm keeps on tracking the knee point in IV curve. Like this there are many problems faced by already installed PV panel. This paper will review the paper on which work is already done.

\section{FACTOR AFFECTING THE PV MODULE PERFORMANCE}

\section{A. solar irradiance:}

Irradiance is the measure of the power density of sunlight received at a location on earth. Due to fluctuations in environmental conditions, temperature change and hence irradiance level changes and is measured in watt per meter square. Whereas irradiation is the measure of energy density of sunlight .The term Irradiance and Irradiation are related to solar component. As the solar isolation keeps on changing throughout the day thus $\mathrm{I}-\mathrm{V}$ and $\mathrm{P}-\mathrm{V}$ characteristics varies.

With the increasing solar irradiance both the open circuit voltage and the short circuit current increases and hence the maximum power point varies. A temperature plays another major factor in determining the solar cell efficiency. The cell voltage reduces by $2.2 \mathrm{Mv}$ per degree rise of temperature [1].

Copyright to IJIREEICE

\section{I-V Characteristics}

The I-V Characteristics is a curve between current and voltage. The area under the I-V curve shows the maximum power that is produce under operating at maximum current and maximum voltage. The area decreases with increase in solar cell voltage due to its increase in temperature.

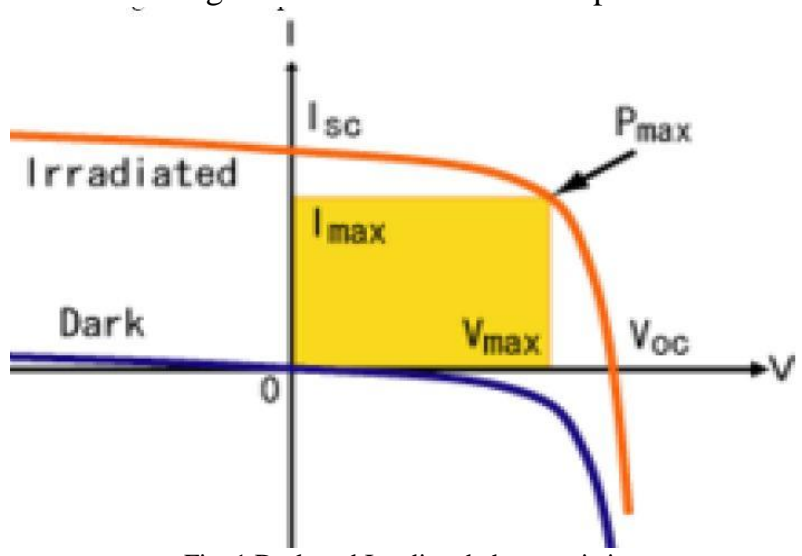

Fig. 1 Dark and Irradiated characteristics

The maximum power point can be obtained by plotting the hyperbola defined by $\mathrm{V} * \mathrm{I}=$ constant.

\begin{tabular}{|c|c|c|c|c|}
\hline SL NO & SET: 1 & VOLTAGE & CURRENT(mA) & POWER(WATTS) \\
\hline 1 & \multirow{9}{*}{$\begin{array}{l}\text { Irradiance: } 48 \mathrm{watt} / \mathrm{m}^{2} \\
\text { Intensity: } 590 \mathrm{lux}\end{array}$} & 16.5 (Voc) & 0 & 0 \\
\hline 2 & & 14.9 & 24 & 0.357 \\
\hline 3 & & 14.6 & 26 & 0.3796 \\
\hline 4 & & 13.9 & 30 & 0.417 (Pmax) \\
\hline 5 & & 11.2 & 36 & 0.40 \\
\hline 6 & & 2.9 & 39 & 0.078 \\
\hline 7 & & 1.2 & 39 & 0.0468 \\
\hline 8 & & 0.5 & 39 & 0.0195 \\
\hline 9 & & 0 & 39 (Isc) & 0 \\
\hline
\end{tabular}

\begin{tabular}{|c|c|c|c|c|}
\hline SL No & SET:3 & VOLTAGE & CURRENT(mA) & POWER(WATTS) \\
\hline 1 & \multirow{9}{*}{$\begin{array}{l}\text { Irradiance: } 115 \mathrm{watt} / \mathrm{m}^{2} \\
\text { Intensity: } 2000 \mathrm{lux}\end{array}$} & 17.7 (Voc) & 0 & 0 \\
\hline 2 & & 17.5 & 28 & 0.49 \\
\hline 3 & & 17 & 46 & 0.782 \\
\hline 4 & & 16.1 & 68 & 1.0948 \\
\hline 5 & & 15.8 & 74 & 1.574 (Pmax) \\
\hline 6 & & 8.8 & 96 & 0.8448 \\
\hline 7 & & 2.2 & 98 & 0.2156 \\
\hline 8 & & 0.1 & 98 & 0.098 \\
\hline 9 & & 0 & 98 & 0 \\
\hline
\end{tabular}


The performance of the PV module is obtained at different tested at STC with irradiance level of $1000 \mathrm{~W} / \mathrm{m} 2$ and irradiance level and intensity. For this above two $25^{\circ} \mathrm{C}$ but in real world condition are constantly changing. observations were taken. For given irradiance and intensity voltage, current and power is calculated and for a corresponding IV characteristics is shown below that systems is affected by the orientation and tilt angle. as indicate the Pmax for different irradiance level. More the irradiance the more is output power of PV module.

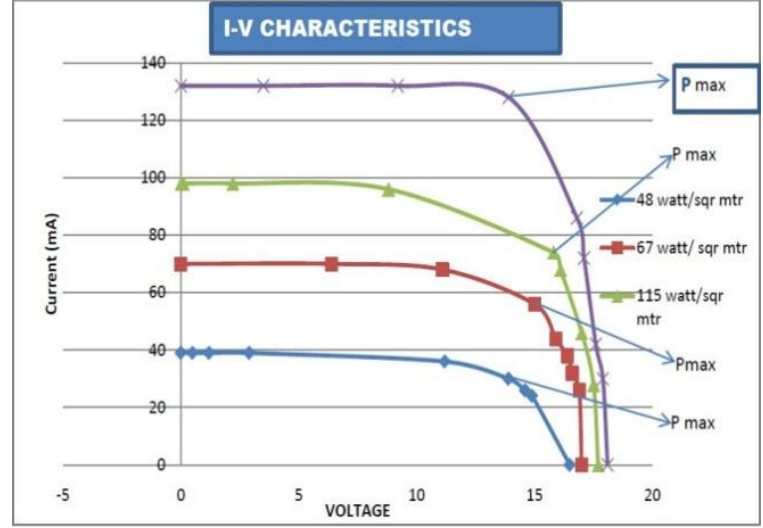

Fig. 2 current versus voltage curve at various irradiance levels and the corresponding maximum power point.

Above example mention in paper [1]. There is one point on the curve that will produce maximum electrical power under incident illumination level. Operating at any other point other then maximum power point will mean that cell will produce maximum thermal power and less electrical power.

\section{MPPT}

The voltage at which PV module can produce maximum power is called maximum power point. MPPT checks the output of PV module and compare it with battery voltage then fixes what is the best power that PV module can produce to charge the battery. Basically MPPT is a dc-dc converter which operate by taking dc for PV module changing it to ac and then convert to a different dc voltage and current to exactly match the PV module to the battery. MPPT uses buck or boost converter for its operation.

\section{B. Temperature:}

Temperatures play another major factor in determining the solar cell efficiency. As the temperature increases the rate of photon generation increases thus reverse saturation current increases rapidly and this reduces the band gap. Hence this leads to marginal changes in current but major changes in voltage. The cell voltage reduces by $2.2 \mathrm{Mv}$ per degree rise of temperature. This result is experimentally proved $[1,10]$. Here the temperature is act as negative factor affecting solar PV performance. The temperature of the module thus should be maintained at room temperature by some means. Solar cell perform better in cold rather in hot climate panel are rated at $25^{\circ} \mathrm{C}$. In hot summer days temperature can easily reach $70{ }^{\circ} \mathrm{C}$ or more it means that panel will produce $25 \%$ less power compared to that they are rated for $25^{\circ} \mathrm{C}$ thus a 100 watt panel produce only 75 watts in May/June in most part of India. Solar panels are

\section{Orientation and Tilt angle:}

The performance of photovoltaic (PV) modules and these parameters determine the amount of solar radiation received by the surface of a PV module in a particular region. Normally the region that lies in the northern hemisphere the panel installed on these building should be facing south or facing the equator and for southern hemisphere facing the north tilt from horizontal at an angle approximately equal to the site latitude. so that maximum irradiance captured. Panel will collect solar radiation more efficiently where the sun rays are perpendicular to the panel surface. For Singapore $\left(1.37^{\circ} \mathrm{N}, 103.75^{\circ} \mathrm{E}\right)$, with very limited land area (country size $720 \mathrm{~km} 2$ ), it is desirable that modules are oriented in such a way as to harness the maximum solar energy possible [2]. For this Comparisons are made for surfaces oriented at $60^{\circ} \mathrm{NE}$ with tilt angles of $10^{\circ}, 20^{\circ}, 30^{\circ}, 40^{\circ}$, and vertically mounted surfaces facing north, south, east, and west. A surface oriented slightly south of due east and with tilt angle of $26^{\circ}$ would yield the maximum annual irradiation of 1562 $\mathrm{kWh} / \mathrm{m} 2$ recorded for the evaluated year. Thus orientation and tilt angle play very important role in PV panel working. Nowadays PV panel rotates according to the light intensity. Panel uses stepper motor to rotate it and programmed with some software. It automatically tracks the position of sun.

\section{Dusts:}

To understand the impact of dust on solar photovoltaic (PV) performance, following factor is to be considering blocking to transmission of sunlight, the increasing of temperature of the and the impact of sunlight transmission which is caused by surface corrosion. Sometimes there is a thick layer of dust accumulated on the surface of PV panels. It significantly affects the performance of PV module. In Shenzhen, Guangdong province, China, it is discovered that under the same solar radiation intensity and outside temperature, the efficiency of PV panels generating with surface fouling is $7.8 \%$, while with the surface cleaning is $9.3 \%$.Thus, there is a more significant impact on the efficiency of PV power generation with dust accumulation on the surface. Therefore, it's necessary to study on the fouling effect to PV power generation projects. When a light of certain intensity falls on dirty PV module the glass cover become heated by multiple refraction. Result in the increase in the temperature of the PV module. Hence the light is blocked this effect of dust on PV module is called blocking effect of fouling (dust). Also dust reduced the irradiated area of the panel and makes the panel partially irradiated. Thus temperature of module rises and for every degree rise in temperature output power efficiency reduced by $0.5 \%$. The dust may be acidic or alkaline thus cause the erosion of the glass cover of the PV module. Due to erosion irradiated area reduced after a long time which reduces the output. Technically the roughness reduced and the reflective index 
of glass cover reduced. Those areas which are very less by the new configuration is approximately twice that of prone to rainfall it become a very big problem. For the traditional configuration.

analysis purpose $\mathrm{PV}$ fouling co-efficient comes into picture.

$$
\alpha=\eta_{2} / \eta_{1}
$$

It is define that in the same light intensity, ambient conditions, the fouling PV panels and clean PV panels power generation efficiency ratio of is the PV-fouling coefficient. Dust in rainy season reduced hence PV fouling coefficient is higher which is desirable. On the other hand in arid area it is found to be lower. So rain plays a very important role in reducing both temperature and dust of PV module [3, 4].

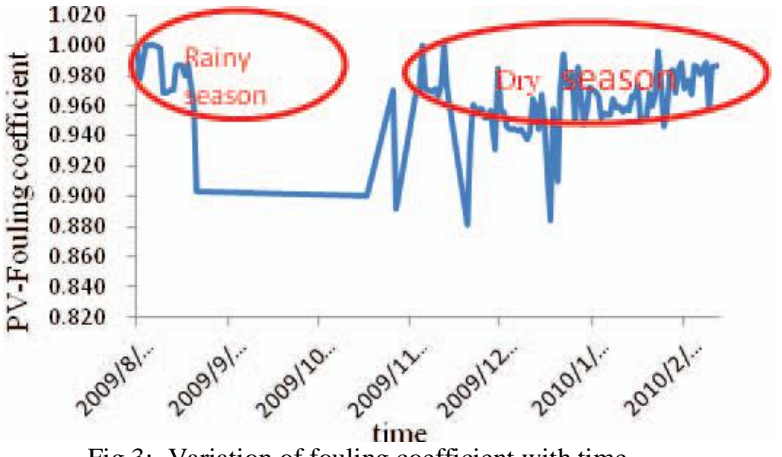

Fig 3: Variation of fouling coefficient with time

\section{E. Shading:}

When selecting the roof area for the photovoltaic array, efforts should always be made to avoid shading or areas known for accumulation of substances that will result in cell shading. Shading is another very important factor that drastically affects the performance of PV module. Solar PV array often subjected to partial shading and rapid fluctuation of the shading. Rapid fluctuation in shading pattern makes maximum power point tracking difficult.

There will exist multiple local MPP and their values will change as rapidly as does the illumination. The shading of the PV module may be by the trees, large buildings construction structure surrounding it. These may cause partial or full shading. The effect of shading is more in the conventional configuration (PV module connected in series) than parallel. Highly parallel-configured PV system that operates effectively in rapidly varying shaded conditions.

PV modules rather than PV cells are connected in parallel and shown to demonstrate better performance in shaded conditions [6,7]. Each PV module is treated as one unit that tracks its own MPP. Therefore, when a module is shaded, the degradation of performance will not propagate to other modules.

The proposed PV system adopts the parallel configuration at the individual cell level, so that every cell in the PV panel can achieve its MPP under non ideal conditions. Under complex irradiance conditions, the power generated

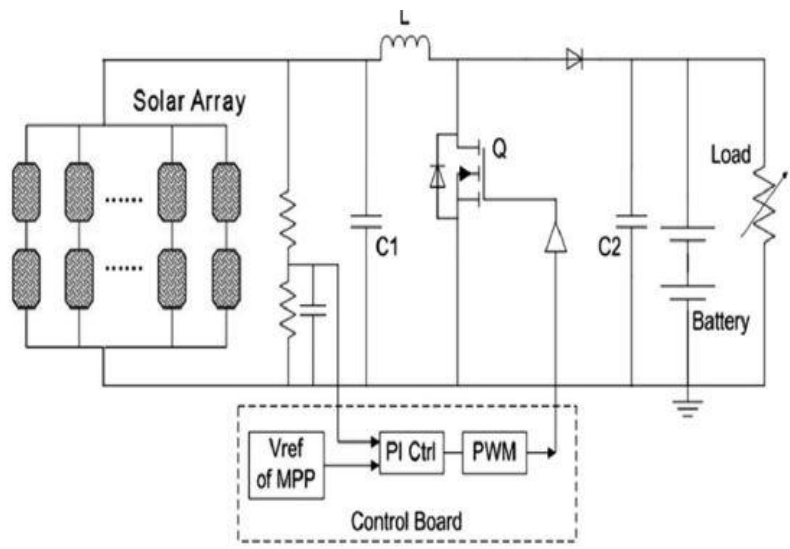

Fig. 4: Circuit diagram of proposed maximally parallel PV system.

The reference configuration is the one with parallel connection of the four panels. It represents the optimal configuration for the maximization of the electrical energy production in case of full irradiated and partially shaded systems. The different configuration is used firstly one panel is shaded then two panel are shaded and so on. Four different results are obtained and corresponding output is calculated.

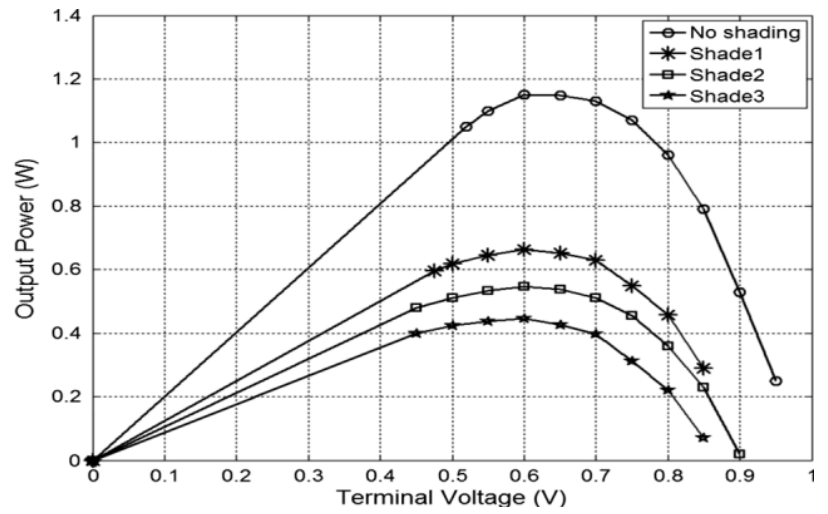

Fig 5: PV curve a for different shading condition

Shading mainly affect the series connected PV module. Since the current produced by shaded portion is less as compared to the illuminated portion. But current in series must be same illuminated cells current forced the shaded portion current to increase result in hotspot and may cause damage to the entire module. for this problem to overcome parallel configuration is used for arranging the PV module.

In parallel the output is not so affected as in case of series configuration. Since the current in parallel is not same in the entire panel but voltage should be same. It is experimentally proved that parallel configuration is better than series. 


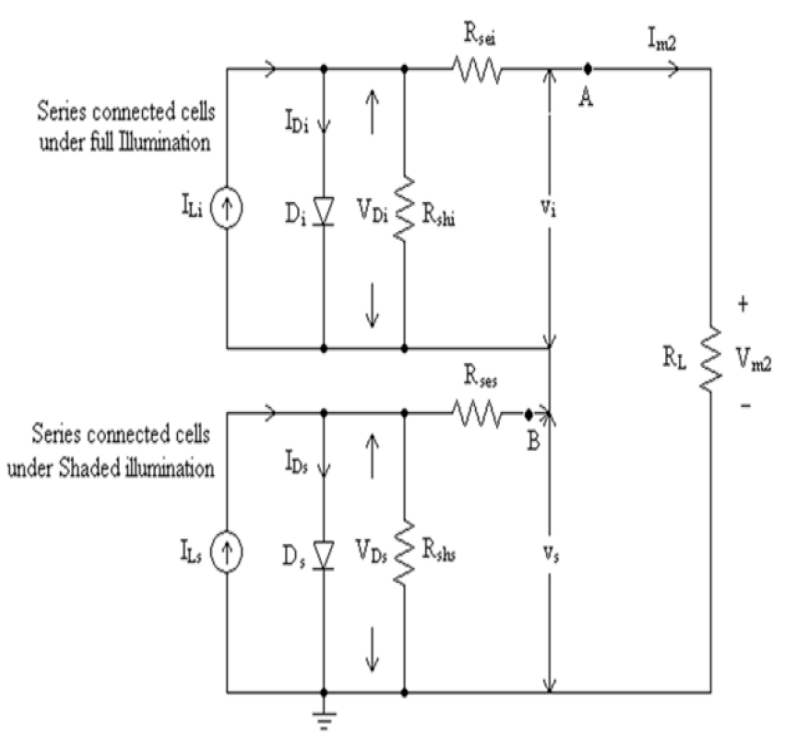

Fig. 6: module consists of 36 cells in series with non-uniform illumination

\section{F. Other Important Factor:}

There are many other important factor that occur in specific environmental condition like desert area, snowfall, hailstorm etc. in seasonal snowfall area the PV module covered with snow for long period of time result in no or very less output power. Hailstorm if directly falls on the module it damages the panel small patches made on it as shown in figure below. This is most likely caused by the prevailing weather conditions such as severe cyclonic storm events with objects or material being lifted from the ground and/or hail which has struck the front or rear of the glass laminated panels. This has allowed moisture to enter the laminated glass as it heats and cools and tracks along the interconnecting wiring and onto the actual wafers. With surface temperatures on the wafers as high as $60^{\circ} \mathrm{C}$ the cracked laminated glass allowed atmosphere to enter the panel. The process of delaminating continued to a point where the resin was allowed to heat up and run to lower parts of the void consequently holding the glass apart by as much as $6 \mathrm{~mm}[5,8]$. This void simply became a well for moisture and contaminants to promote decay and corrosion. The corrosion of module leads to complete degradation of the module result in no output from the module. Thus it is advisable to place the PV module in such a location which is away from such type of problem.

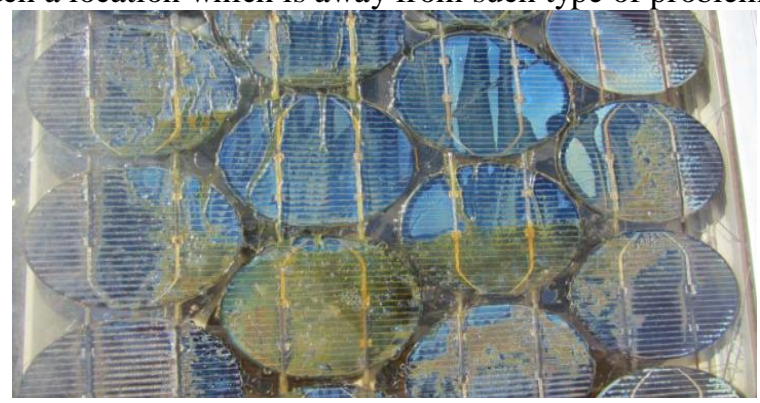

Fig. 7: Degration of PV module

\section{G. Critical factor:}

The critical factors investigated in this study are the mounting roof materials, mounting heights, solar radiation levels and types of PV modules. As with all PV technologies, the power production is a negative function of temperature, thus knowledge of the optimum mounting parameters will directly affect output. In this work, monocrystalline and poly-crystalline PV modules were each installed on two mock-up roofs with roofing material of concrete tiles and metal deck. The air gap between the roof surfaces and the PV modules was varied a between $0 \mathrm{~cm}$, $10 \mathrm{~cm}$ and $20 \mathrm{~cm}$.

\[ T_{\text {cell }}=T_{\text {amb }} \Delta T \]
Where
$T_{\text {amb- ambient air temperature }}$
$T_{\text {cell- operating cell temperature }}$
$\Delta \mathrm{T}$-temperature difference
G-solar radiation

The methodology used in this paper is to compare the performance of the PV module on different type of rooftop made up of different material one is of concrete and other one of metal [9]. The mounting air gap heights between the top surface of the roof and back surface of the retrofitted PV array were: $0 \mathrm{~cm}(\mathrm{H} 1), 10 \mathrm{~cm}(\mathrm{H} 2)$ and 20 $\mathrm{cm}(\mathrm{H} 3)$. After performing the experiment it was found that change in temperature is dependent on type roofing material, PV technology, solar irradiance and also height of air gap. The change in temperature ranges from the lowest at $2.5^{\circ} \mathrm{C}$ for Poly-Metal at $\mathrm{H} 1$ at $\mathrm{G} 1$ to $25.1^{\circ} \mathrm{C}$ for Mono-Concrete at $\mathrm{H} 1$ at G3. The Tcell of crystalline silicon PV modules on concrete roof are consistently higher than the metal roof installation. With respect to the PV technology, mono-crystalline modules have higher Tcell than poly-crystalline modules on both types of roofing material. Tcell increases with solar radiation and decreases with height of air gap H. so it is concluded that this factor also to be consider.

\section{CONCLUSION}

This paper review the analysis of the work performed related with the PV module. The factors discussed in this paper are very important that affect the performance of the PV panel. If these factor are not considered in installation and working of panel it may drastically reduce the electrical output power which result in the loss of capital invested in the project. If these factors are taken care the output and capacity of the solar power sector can be improved in our country. It is seen that irradiance, temperature, orientation, tilt angle, shading, dusts are some major factor affecting panel performance. So adequate technique should be developed to mitigate these problems.

\section{REFERENCES}

1 Pradhan Arjyadhara1, Ali S.M2, Jena Chitralekha3, "Analysis of Solar PV cell Performance with Changing Irradiance and Temperature", 1 Jan 2013 Page No. 214-220. 
2 Yong Sheng Khoo, Andr'e Nobre, Raghav Malhotra, Dazhi Yang, Member, IEEE, Ricardo Ruther, Thomas Reindl, and Armin G. Aberle, Senior Member, IEEE, "Optimal Orientation and Tilt Angle for maximizing in-Plane Solar Irradiation for PV Applications in Singapore", vol :4, issue:2, Publication Year: 2014, Page(s): $647-653$

3 Malay Mazumder, Mark Horenstein, Jeremy Stark, Peter Girouard , Robert Sumner, Brooks Henderson\ Omar Sadder\ Ishihara Hidetaka, Alex Biris, and Rajesh Sharma, "Characterization of Electrodynamics Screen Performance for Dust Removal from Solar Panels and Solar Hydrogen Generators", volume: 49 , issue:4 Publication Year: 2011 , Page(s): $1-8$.

4 Fali Ju, Xiangzhao Fu, "Research on Impact of Dust on Solar Photovoltaic (PV) Performance" Publication Year: 2011, Page(s): $3601-3606$.

5 Farid Touati, Mohammed Al-Hitmi and Hamdi Bouchech, "Towards Understanding the Effects of Climatic and Environmental Factors on Solar PV Performance in Arid Desert Regions (Qatar) for Various PV Technologies", Publication Year: 2012 , Page(s): $78-83$.

6 R. Candela, V. Di Dio, E. Riva Sanseverino, P. Romano, "Reconfiguration Techniques of Partial Shaded PV Systems for the Maximization of Electrical Energy Production",Publication Year: 2007 , Page(s): $716-719$.

7 Lijun Gao, Senior Member, IEEE, Roger A. Dougal, Senior Member, IEEE, "Parallel-Connected Solar PV System to Address Partial and Rapidly Fluctuating Shadow Conditions", volume:56, issue:5,Publication Year: 2009 , Page(s): 1548 - 1556.

8 N.Z. Zakaria, H. Zainuddin, S. Shaari, S.I. Sulaiman, R. Ismail, "Critical factors affecting retrofitted roof-mounted Photovoltaic arrays: Malaysian case study", Publication Year: 2013, Page(s): $384-388$.

9 Allan Gregg, Terence Parker, and Ron Swenson, "A Real World Examination of PV System Design and Performance".

10 Furkan Dinçer, Mehmet Emin Meral, "Critical Factors that Affecting Efficiency of Solar Cells".

11 Ramaprabha Ramabadran. "Effect of Shading on Series and Parallel Connected Solar PV Modules". Vol 3,no. 10, 2009.

\section{BIOGRAPHIES}

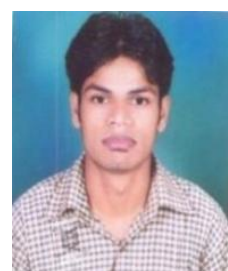

Subhash Kumar is a ME scholar in the Electrical Engineering department, PEC University of Technology Chandigarh India. He received bachelor of Electrical Engineering (B.Tech) degree in 2012 from NIT Kurukshetra Haryana. His research interests are solar PV performance, estimation of solar of resource.

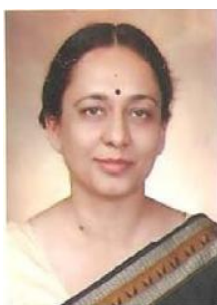

Dr. (Mrs) Tarlochan Kaur received her B.E (Honours), M.E and Ph.D degree of Electrical Engineering from PEC University of Technology, Chandigarh. Her area of research interest includes Electromagnetic Fields, Power systems and Renewable Energies. She has to her credit over 50 published research papers in various Journals, International and National conferences. She has contributed many articles in the newspapers. She is currently working as Head \& Associate Professor in Electrical Engineering Department in PEC University of Technology, Chandigarh. 